\title{
A Study on Chinese Traditional Culture Education in China's Kindergartens
}

\author{
Jinling Tao ${ }^{1 *}$, Jianjun Yin ${ }^{2}$ \\ ${ }^{1}$ College of Education Science, NanTong University, China. \\ ${ }^{2}$ College of Education Science, Yangzhou University, China.
}

\begin{abstract}
This study investigated the current situations of the Chinese traditional culture education in China's kindergartens. A total of nine hundred 900 teachers from different ranked kindergartens in six province and one municipality were selected for questionnaires, on-site observation and interviews. The education practices in the seven kindergartens of the two cities were observed on sites. The students and their parents or grandparents were interviewed. This study demonstrated that the concept of Chinese traditional culture education is not clear among the groups selected for study; the teachers are not well versed in Chinese traditional culture; the education activities lack diversity; and the integrality of the education is weak. In order to develop the Chinese traditional culture education, it was recommended that the concept of traditional culture education should be established academically; the goal of the education should be set appropriately; a rich content of the education should be selected and the diverse resources of traditional culture education should be integrated.
\end{abstract}

Keywords: Chinese kindergartens; Traditional culture, Traditional culture education

\section{INTRODUCTION}

Traditional culture is a nation's creation in the real life and its accretion in a long history. It demonstrates the life style and the value system of the nation. It is the symbol of the spiritual life of many generations. It is the outcome of the nation's great effort to harmoniously live with the nature and historical environment in long history. Every nation has its own traditional culture, which is the symbol of the nation and the basis of the nation's existence. The traditional culture provides a crucial element for the nation's development as a unity. However, the traditional cultures of many nations all over the world are facing the risk of extinction under the pressure of the growth of the modern culture. The culture gaps between different generations appear in many nations. Eduard Spranger noted that the task of education is to pass down culture, experience cultural value and cultivate the persons who are able to create cultural value [1]. In the book Education and Culture, E. Spranger claimed that education is a cultural process and proposed the only solution for cultural crisis [2]. He believed human is a cultural being. Human's history is the history of culture. Therefore, the process of education is a procedure of the cultural development in history. Kindergarten education is the enlightenment and the foundation in people's lives. Its impact on the students lasts for a whole life. Thus, it is necessary to create rich and diverse experiences of traditional culture for the students and plant the seed of traditional culture in their hearts so that they may pass on the legacy of the traditional culture.

\section{SAMPLE AND METHOD}

\subsection{Sample}

Randomly stratified sampling method was applied to select the kindergartens as samples from six provinces and one municipality such as $\mathrm{J}$ province and $\mathrm{S}$ province. The selected samples included urban kindergartens, urban-rural integrated kindergartens and rural kindergartens which took up to $48.8 \%, 13.4 \%$ and $37.8 \%$ of the total number of the samples, respectively. Among them, $60.2 \%$ kindergartens are ranked as province-model, $30.5 \%$ as city-model, and $9.3 \%$ as normal level. Nine 
hundred teachers of these kindergartens received questionnaires. And 864 questionnaires were collected. Among them, 840 questionnaires were applicable and used in this study. The rate of effective collection of the questionnaires reached $93.3 \%$. Among the selected teachers, only three are male, and all of others are female. And $23.7 \%$ of them are under 25 years old; $22.4 \%$ are between 26 to 30 years old; $9.3 \%$ are between 30 to 40 years old; $8.5 \%$ are between 41 to 50 years old; $2.8 \%$ are above 50 years old. Regarding to their education levels, $35.4 \%$ have Bachelor's Degrees; $56.5 \%$ have college diplomas; and $8.1 \%$ have been just high school educated. Regarding to their major, $81.3 \%$ of them majored in preschool education; $8.9 \%$ did not graduate from preschool education major but other majors in education field; and $9.8 \%$ graduated from non-education majors. The activities of traditional culture education in seven kindergartens in $\mathrm{N}$ city and $\mathrm{F}$ city were observed. After the activities, some of the parents, grandparents, and the students of middle classes and top classes were interviewed.

\subsection{Method}

2.2.1. Questionnaires were used to collect the information of the kindergartens (e.g. names, features, ranks), the teachers (genders, education levels, class grades, years of teaching, titles, etc.), and the activities of traditional culture education (goal, content, method, means, frequency, etc.).

2.2.2. On-site observation was conducted. In order to know the current situations of the education, the activities of traditional culture education in seven kindergartens in NanTong, WeiFang and NanJing cities were observed on site but without participation.

2.2.3. Interviews with the teachers, the parents and grandparents of the students were accomplished through internet, phone and face to face conversation, in order to know their knowledge on traditional culture education. In addition, the students in middle classes and top classes were interviewed immediately after the activities.

\subsection{Statistical Analysis}

The SPSS 19.0 was used to analyze the collected questionnaires to obtain the percentages of the descriptive statistical results. The interviews with teachers, parents, grandparents and students were analyzed. The designs of the activities, records of observations and the products of the students which were made in the activities were analyzed as well.

\section{RESUlt}

\subsection{The Concept of Traditional Culture Education is not Clear}

In the questionnaires, $53.7 \%$ of the teachers believed the traditional festival customs are highly beneficial to the growth of children; $40.2 \%$ of them believed the customs are averagely beneficial; $6.1 \%$ of them believed they are just normally good. None of them believed they are not beneficial at all or not so beneficial. Regarding to other traditional culture items, most of the teachers believed they are averagely beneficial. Through the interviews, it is known that many teachers and parents did not clearly or accurately understand the value of traditional culture education. They emphasized on the knowledge and skills of traditional culture but neglected the importance of the affectional influence of the traditional culture. Some parents considered traditional culture education as "the restoration of history", "reading ancient poems and books", "learning traditional manners", etc. On-site observation of the activities also confirmed the conclusion that people usually believed knowledge is more important than affectional experiences. Therefore, teachers and parents did not correctly understand the traditional culture education in kindergartens. The goal of traditional culture education should be clarified.

\subsection{The Teachers are not Well Versed in Chinese Traditional Culture}

The teachers' understanding on twenty-five traditional cultural items, which are cataloged into four groups: traditional customs, traditional literature, traditional arts and traditional sports, were studied. $48.4 \%$ of the teachers have rich knowledge on traditional customs but only have basic understanding on other items. In the interviews, most of the teachers claimed they never received systematic and specialized training on traditional culture education. Even though they think they have basis understanding on some traditional cultural items, they are unable to conduct the education on those items because they are short of practical experiences. In the interviews with grandparents and parents, 
it is obvious that grandparents know much more traditional culture and are more interested in it than the parents. The study reveals that the teachers are not very well versed in traditional Chinese culture. They lack basic knowledge and skills of traditional culture; know little on the deeper concept of traditional culture. Therefore, the development of education activities is hindered. So their ability of conducting traditional culture education need to be improved.

\subsection{The Education Activities Lack Diversity}

The application frequency of twenty-five traditional cultural items, which are cataloged into four groups: traditional customs, traditional literature, traditional arts and traditional physical trainings, were studied. $54.1 \%$ of the teacher most frequently applied traditional festival customs as their education items. However, all of the other twenty-four items, such as folk opera, folk stories, and folk toys and so on, are not applied often. The interviews with teachers, parents and grandparents demonstrated the education activities lack diversity, which is in accordance with the conclusion of the questionnaires. The Lantern Festival, Dragon Boat Festival, Mid-autumn Festival, are the most educated festivals. Even though Spring Festival is the most important festival in Chinese traditional culture, it is not the primary selection of teachers. The education contents should be diversified.

\subsection{The Integration of the Education is Weak}

The questionnaires showed that $89.4 \%$ of the traditional culture education activities are held in kindergartens, $7.8 \%$ are in homes, and only $2.8 \%$ are in public cultural facilities such as community museums and theaters. The same result can be found through the on-site observations and interviews. Kindergarten is the only one major resource of traditional culture education. However, other resources such as homes, communities, museum, culture clubs, theaters, are not used sufficiently and thus do not play its functions very well in traditional culture education. These resources should be used in future.

\section{DISCUSSIONS AND RECOMMENDATIONS}

The National Ministry of Education issued the Complete Excellent Chinese Traditional Culture Guidance in 2014, in which it was noted that it is so important and urgent to strengthen the excellent Chinese traditional culture education and the guidance to improve the education is also put forward. General Office of The Communist Party of China Central Committee and General Office of the State Council issued the Opinions on The Implementation of The Chinese Traditional Culture Heritage Development Project, in which early childhood education is categorized into the field of traditional culture education. In this paper, the suggestions to the traditional culture education in kindergartens are proposed as below.

\subsection{Recommendations: Establish the Academic Concept of Traditional Culture Education}

The process of education is the formation of students' personalities in culture. Culture is the foundation of education. Education is the key of the preservation of culture. German educator Friedrich Adolph Wilhelm Diesterweg, influenced by Johann Heinrich Pestalozzi's educational theory of naturalism, proposed that social culture should be concerned in education besides the Principle of Natural Adaptability which was proposed by the former educator. He believed education should not only match the children's physical and psychological development but also accord with the social culture, especially its national culture and local culture $[3,4]$. The curriculum in kindergartens is the selected and organized contents with the integrated and helpful experiences for a clear purpose based on the features of children's physical and psychological development and the background of social culture [5]. Educators should select the best from their rich cultural accumulation; meanwhile, the selected contents also should match the learning abilities of children. In this way, the text of kindergartens curriculum may be formed [6]. Traditional culture is a nation's creation and accretion in real lives in a long history. It demonstrates the life style and the value system of the nation. It is the symbol of the spiritual life of many generations. It is the outcome of the nation's great efforts to harmoniously live with the nature and historical environment in a long history. Traditional culture belongs to the nation and to the world as well.

Under the trend of globalization and the impact of foreign culture and commercial culture, the inheritance and continuity of good traditional culture is in crisis and must be concerned. Considering 
the dislocation of the traditional culture, early childhood education as the enlightenment of lives has the obligation to spread the concept of national culture and awaken the nation's awareness of the inheritance of traditional culture. Educators should realize the responsibility and make great efforts to development their own knowledge of traditional culture and the ability of educating traditional culture. They should rationally analyze and select the contents for the purpose of children's development and consistently create new ideas and methods with a worldly broad mind regarding to traditional culture. Thus, they will establish open-minded and advanced concept of traditional culture education, and have the capability to fulfill the responsibility and mission of spreading, inheriting and promoting the good traditional culture elements.

\subsection{Set an Appropriate Goal of Traditional Culture Education}

Traditional culture education is not an addition of the existing courses, but the reconstruction of the courses from a new perspective. The reconstructed kindergarten courses are harmony, which is in consistent to the harmony development of children. The education goal is the starting point and end of education. The process from the possibility of the goal to its feasibility is a process of integrationdistribution-integration. It is a harmony unity of hierarchy and integration. It is not only the specialization and distribution in a single field, but also the gradual development of many fields as a unity. It does not only emphasize the knowledge and skills but also focuses on the influence of traditional culture on children's emotion and attitudes. Traditional culture education in kindergartens is not aimed at teaching knowledge or skills of traditional culture, but to experience the affectional connotation, share the joy from traditional culture and establish the identification and confidence with traditional culture through diverse activities. The goal of the traditional culture education in kindergartens should be set for the development of children according to their ages and personalities. It is not right to use a single standard upon all children. Instead, the goal should be different from person to person. Taking the dragon dance in the Lantern Festival as an example, the purpose is not only to teach the knowledge and grasp the skills about dragon dance, but also to understand the spirit of national unity and cooperation which is demonstrated by dragon dance. Taking traditional festival activities as another example, educator can use the most typical and well-known customs as an educated content. However, primary classes may emphasize on participating in the activity and experience the festival environment; middle classes may emphasize on understanding the deep connotation of the festival; the top classes may create and enrich the activities. The goals of the classes become gradually deeper according to the students' ages. The students not only know the knowledge and grasp the skills but also understand the national mind, moral ethics, spirit, value and aesthetic. Therefore, the national confidence and culture pride will be arose through understanding the nation's wisdom. BoTong Street Elementary School in WeiFang city is a good example. The Lantern Festival was educated in this school. The primary class students were taught to make rice dumpling so that they may taste the food of the Lantern Festival; middle class students were taught to make colored lantern and other decorations so that they may develop their carefulness and patience and enjoy the beauty of the colored lantern; the top class students were taught to make land boat and dragon lantern with recycled material and organized the program of running the land boats and dragon dance so that they may develop their creativity and understand the culture connation of the festival.
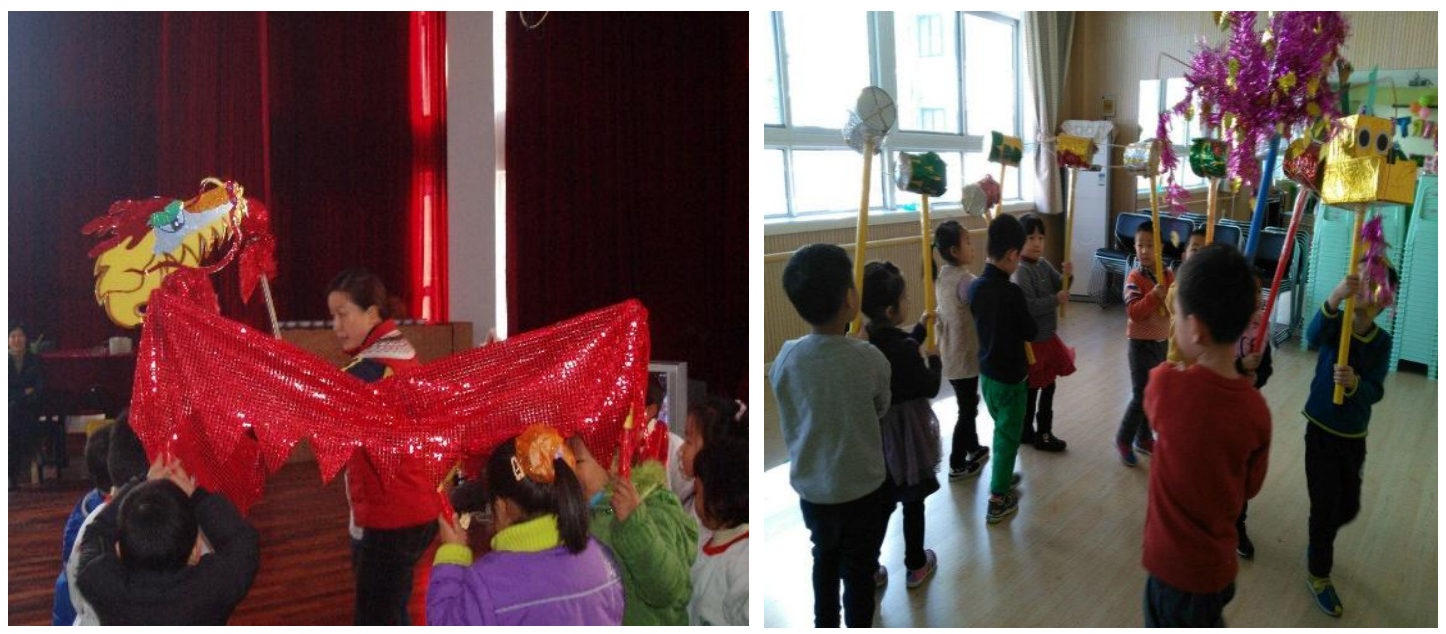


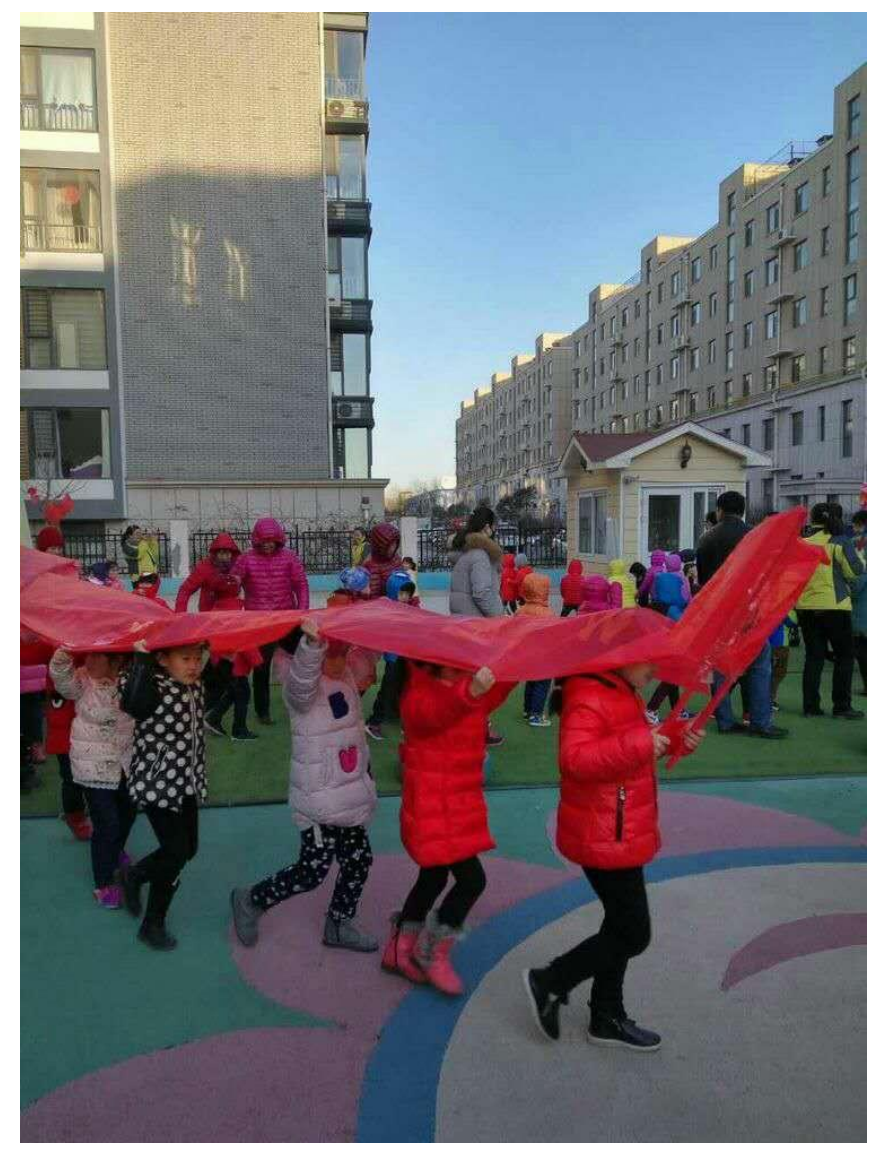

Dragon Dance

\subsection{Rich Educated Contents should be Embraced}

Chinese traditional culture is very rich and broad. For example, there are traditional customs and traditions (e.g. marriage customs, festivals, and the tradition of respecting the elders), traditional folk arts (e.g. folk arts, crafts and sculptures), folk music (e.g. folk songs, dances and operas), folk literatures (e.g. folk poems, stories and legends), folk sports (e.g. folk games, Kong Fu, and physical competition) and so on. All of the Chinese traditional culture elements demonstrate regional and national diversity and unity as well. This diversity and unity can be found in Yue Ju of Zhe Jiang, Yu Ju of He Nan, Huangmeixi of An Hui, Lu Ju of Shanghai, Er Ren Tai of Neimenggu, Er Ren Zhuan of Northeast, Ci Xiu of Su Zhou, Ni Ren of Wu Xi, Bian Zhu of Si chuan, Zi Sha Hu of Yi Xing, Ci Qi of Jingdezhen, Bu Long of Han Zu, Long Deng of Tong Zu, Wen Shi of North, Wu Shi of South, and so on. Traditional culture education in kindergartens has the solid foundation of national culture, and should be appropriate for the development of children. The educators should exploit the rich traditional culture resources. Considering the feasibility and possibility of the education practice, the educators should select the proper and good resources. In this way, the curriculums would be developed based on the current situations, interests and the need of students and also is appropriate to the schools, classes, local resources and individuals. Thus, traditional culture education would be a part of children's lives. The classes would show unity and integration. They cover many filed of education and make good balance. Such education would demonstrate the features of nationality, enlightenment, fun and scientificity. For example, the folk games Ding Niu, Dou Jiao, Tai Hua Jiao, Chao Huangdou, Fan Hong Sheng, Tiao Pi Jin, Gun Tie Huan, are all attractive to children and loved by them. For another example, Beijing opera, which is known as the quintessence of Chinese national culture, is a comprehensive art. It has rich and deep culture basis. Its facial masks, costume, stage property, the four performing techniques and good stories can be used to build up a comprehensive 
class network, which shows the beautify of the contents, singing styles, costumes, makeup and stage property to the students. In Xinhua Kindergarten, WeiFang City, the teacher Jingdong Ji who has the talent of singing Beijing opera, taught the class "Little Opera Fans", which was incorporated with watching opera, learning opera, drawing facial masks and making tools in the classes. The classes stimulated the interests and passion of the students on Beijing opera. Another teacher, Yujing Xv, who has experiences of running land boat, organized a series of activities of the Lantern Festival by making land boat, dragon lantern and dragon dancing.
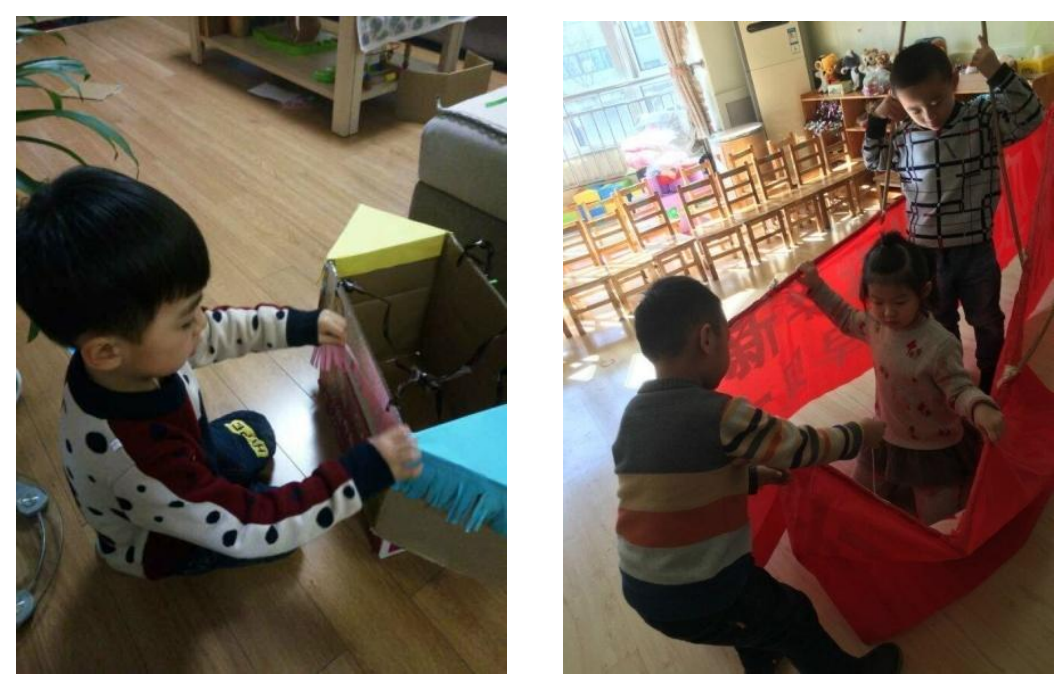

Making Land Boats
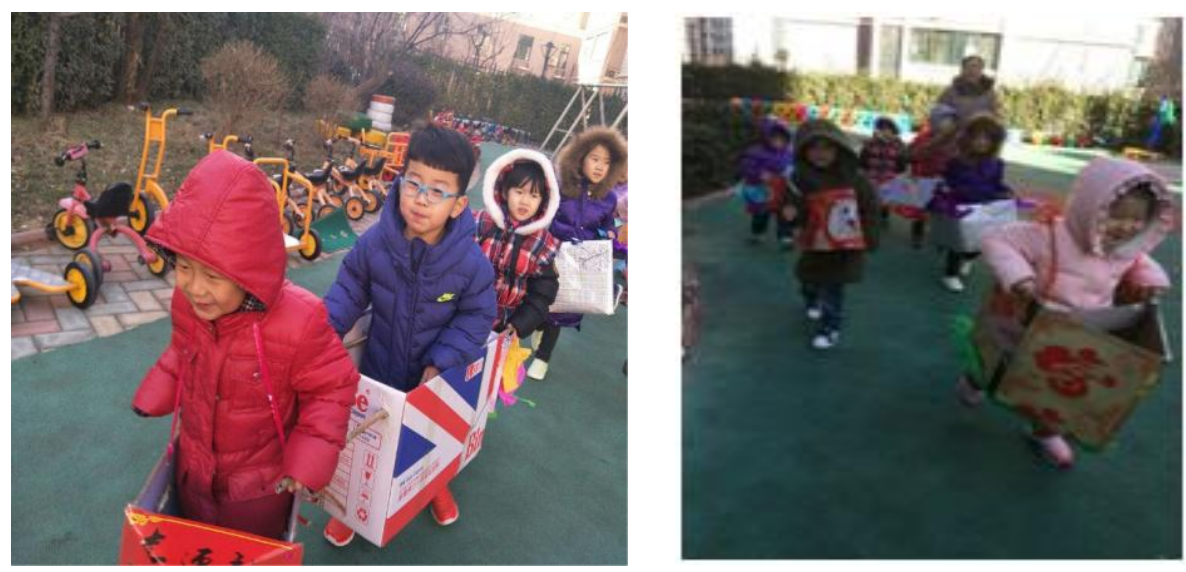

Running Land Boats

\subsection{The Diverse Resources of Traditional Culture Education should be Integrated}

4.3.1. The educators should review and categorize Chinese traditional culture items, investigate and collect good cultural heritages. Then, the proper traditional culture items may be selected to build up a data base of traditional culture resources, which would be a reference for traditional culture education in kindergartens.

4.3.2. Professional education training should be offered to the teachers before they go to work and after they have some working experiences. The teachers may go out of school to be trained by some experts, or some experts may be invited to schools to train teachers. In addition, human resources in the society should be encouraged and invited to participate in school's education programs. Some parents and residents in the community who have talents in traditional culture, folk artists or heritage inheritor can be hired by kindergartens as the advisers of traditional 
culture education. In this way the human resources of traditional culture education may be enriched. For example, Mehuashanzhuang Kindergarten invited Shadow Play troupe to the school to make the Shadow Play tools and play the drams for the students. Moreover, the troupe trained two teachers of the kindergarten to be the Heritage Inheritor of Shadow Play. Xinhua kindergarten in WeiFang city invited a masseur to do massage for students. BaoTong Street Kindergarten in WeiFang city invited experts on Chinese medicine to teach students to recognize Chinese traditional medicines in a plantation. DiJing Kindergarten in WeiFang city invited Chinese calligraphers to participate in the Spring Festival activities to write the Chinese letter of blessing and paste spring couplets with students.

4.3.3. A system incorporated with kindergartens, families, communities, protection centers of Intangible Cultural Heritage, and literary federation should be established. In this way, all resources can be integrated and used. Folk artists, talents, heritage inheritors should be invited to participated in traditional culture education. The circles of traditional culture education, exhibitions and shows of traditional culture should be built up through the establishment of museums, culture clubs, theaters and Intangible Cultural Heritage centers. Diverse education basis would be formed, which is a system incorporated with families, communities, kindergartens.

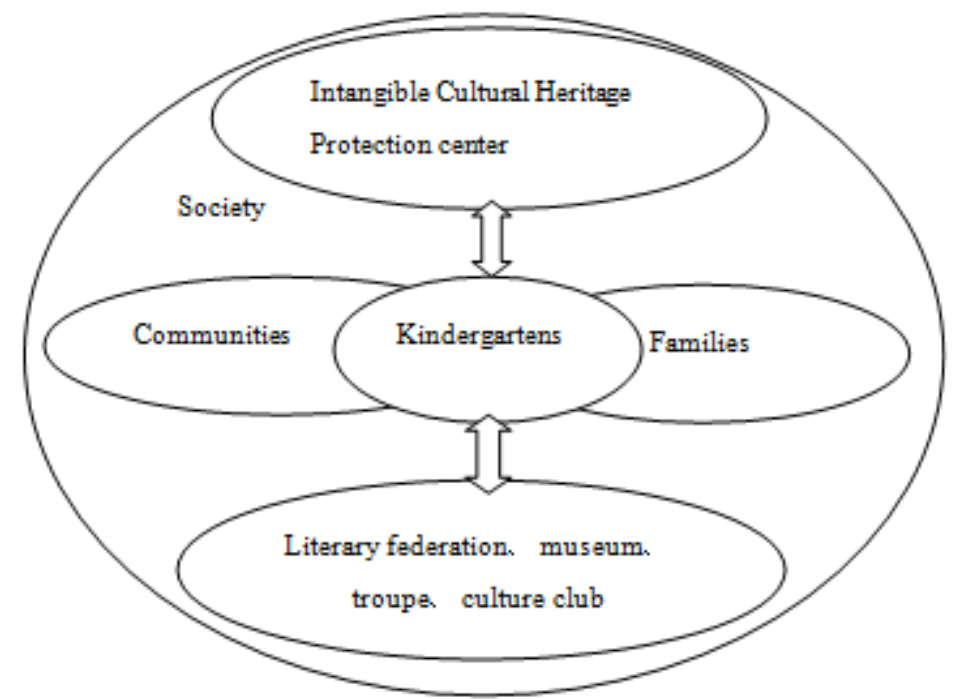

Incorporated system of traditional culture education in kindergartens

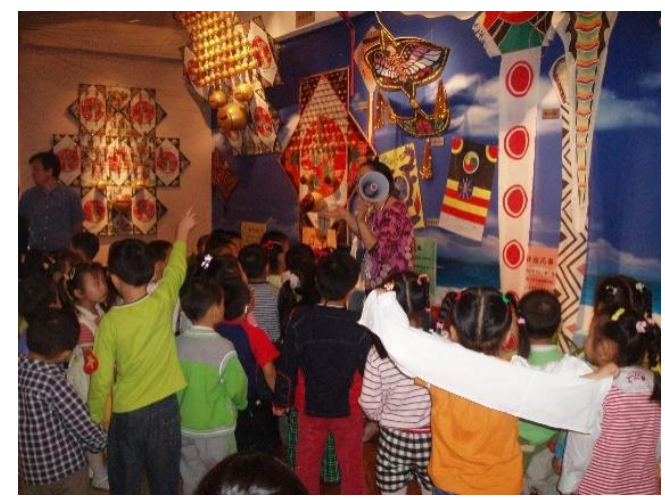

Visitation in Kite Museum

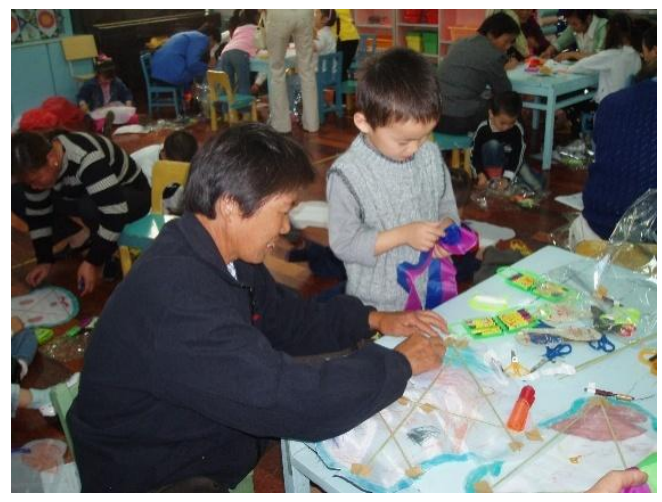

Making Kites

Kindergartens can invite experts of traditional culture to do some seminars to help parents understand the background, the meaning of the traditional culture education so that the parents may cultivate an atmosphere of traditional culture at their homes. The parents who have some talents in some aspects of traditional culture may be invited to participate in the design, preparation and practice of education 
and promotion the traditional culture. For example, some parents may collect the folk games for schools. In the kite festival, parents may make kites, play kites with their children together. Residents in the communities around kindergartens may be invited to contribute their abilities and talents of traditional culture to the school's education. In this way, people understand and care traditional culture education much more. The education thus reaches the families and society. Also, students may go out from school into communities, museums, theaters, and families to conduct the activities of traditional culture. Through the real and vivid experiences, students understand the connection between the traditional culture and people's daily life. Education in kindergartens, education in family and education in society should be incorporated together. Kindergarten is still the main education basis. But families and society could in greater efforts support the major role of kindergarten. In this way, education resources are integrated. Kindergarten, families and society are united in traditional culture education.

\section{ACKNOWLEDGEMENT}

Shandong Province Social Science Planning Research Project "Research on the Inheritance of Chinese Excellent Traditional Culture in Kindergarten from the Perspective of Educational Ecology "15CWHJ04"

\section{REFERENCES}

[1] Jinhong Ding. The Foundation of Pedagogy. Beijing: Higher Education Press, 2009: 13, 14.

[2] Rongchang Zhao, Jizheng Zhang. Foreign Education on the election. Nanjing: Jiangsu Education Press, $1990: 285$.

[3] Diesterweg. The German Teacher Training Guide. Yuan Yiying translation. Beijing: People's Education Press, 2001 : 169.

[4] Yongping Yu. On kindergarten curriculum and its characteristics. Early education, 2001 (1).

[5] Yongping Yu. Culture, folk art and kindergarten curriculum [J]. Pre-school curriculum research, $2001(1)$.

\section{AUTHORS' BiOgRAPHY}

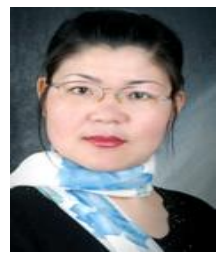

Jinling Tao, Ph.D, is an associate professor of education in the College of Education Science at Nantong University. She directs thesis for master level students and her areas of research includes preschool curricula and preschool instructional theory. She can be reached by email at tjling2000@yeah.net

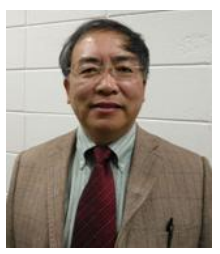

Jianjun Yin, Ph.D, is a guest professor of education in the College of Education Science in Yangzhou University. He holds permanent professorship at Jackson State University. He can be reached at jianjun.yin@jsums.edu 